Cite this: Phys. Chem. Chem. Phys., 2014, 16, 3055

Received 31st October 2013, Accepted 2nd January 2014 DOI: $10.1039 / c 3 c p 54604 \mathrm{~g}$

www.rsc.org/pccp

\section{A promising $\mathrm{Na}_{3} \mathrm{~V}_{2}\left(\mathrm{PO}_{4}\right)_{3}$ cathode for use in the construction of high energy batteries}

\author{
Weixin Song, ${ }^{a}$ Xiaobo Ji, ${ }^{a}$ Yinpeng Yao, ${ }^{a}$ Hanjun Zhu, ${ }^{a}$ Qiyuan Chen, ${ }^{a}$ Qinqin Sun ${ }^{a}$ \\ and Craig E. Banks*b
}

High-energy batteries need significant cathodes which can simultaneously provide large specific capacities and high discharge plateaus. NASICON-structured $\mathrm{Na}_{3} \mathrm{~V}_{2}\left(\mathrm{PO}_{4}\right)_{3}$ (NVP) has been utilised as a promising cathode to meet this requirement and be used in the construction of high energy batteries. For a hybrid-ion battery by employing metallic lithium as an anode, NVP exhibits an initial specific capacity of $170 \mathrm{~mA} \mathrm{~h} \mathrm{~g}{ }^{-1}$ in the voltage range of $1.6-4.8 \mathrm{~V}$ with a long discharge plateau around 3.7 $\mathrm{V}$. Three $\mathrm{Na}(2)$ sites for NVP are found capable to be utilised through the application of a wide voltage window but only two of them are able to undergo ions exchange to produce a $\mathrm{NaLi}_{2} \mathrm{~V}_{2}\left(\mathrm{PO}_{4}\right)_{3}$ phase. However, a hybrid-ion migration mechanism is suggested to exist to describe the whole ion transport in which the effects of a $\mathrm{Na-ion} \mathrm{"barrier"} \mathrm{results} \mathrm{in} \mathrm{a} \mathrm{lowered} \mathrm{ion} \mathrm{diffusion} \mathrm{rate} \mathrm{and} \mathrm{observed} \mathrm{specific} \mathrm{capacity.}$

\section{Introduction}

Lithium-ion battery (LIB) technology is critically needed for many applications in a plethora of industries and is an important energystorage solution which can be potentially applied, for instance into electric vehicles (EVs). ${ }^{1,2}$ However, LIB has continued to be primarily relegated by the electronics market mainly due to its cost and material issues ${ }^{3}$ and the lack of high-performance cathode materials have become a technological bottleneck for the commercial development of advanced LIB. ${ }^{4}$ Particularly for the entrance of LIB into high energy fields, such as EVs and renewable energy storage in smart grids, the demand for highcapacity and voltage cathodes is starting to become a key focus of research.

In the search for new positive-electrode materials for LIB, recent research has focused upon nano-structured lithium transitional-metal phosphates that exhibit desirable properties such as high energy storage capacities combined with electrochemical stability. ${ }^{5,6}$ Olivine $\mathrm{LiFePO}_{4},{ }^{7}$ as one member of this class, has risen to prominence so far due to other characteristics involving low cost, low environmental impact and safety, which are critical for large-capacity systems to be implemented. Nonetheless, olivine also has some shortcomings including the

\footnotetext{
${ }^{a}$ Key Laboratory of Resources Chemistry of Nonferrous Metals, Ministry of Education, College of Chemistry and Chemical Engineering, Central South University, Changsha, 410083, China. E-mail: xji@csu.edu.cn; Fax: +8673188879616

${ }^{b}$ Faculty of Science and Engineering, School of Science and the Environment, Division of Chemistry and Environmental Science, Manchester Metropolitan University, Chester Street, Manchester M1 5GD, Lancs, UK.

E-mail: c.banks@mmu.ac.uk; Fax: +44(0) 1612476831
}

one-dimensional lithium-ion transport and two-phase redox reaction that together limit the mobility of the phase boundary as well as the emerging safe hazard. ${ }^{6}$ Meanwhile, the availability of readily-accessible lithium is a key concern and as supplies reduce, costs will rise which will be passed on to the end consumers such that Li-ion batteries will become too costly. ${ }^{8}$

Recently, tremendous attention has been focused on sodiumion batteries (SIB) with NASICON (a Na superior conductor)structured compounds been brought to the forefront of scientific investigation. These NASICON-type compounds are lithium ion free, and as such overcome the inherent disadvantages as described above. The NASICON-type compounds based materials feature a highly covalent three-dimensional framework that generates large interstitial spaces through which sodium ions may diffuse, ${ }^{9,10}$ with compounds such as $\mathrm{Na}_{3} \mathrm{M}_{2}\left(\mathrm{PO}_{4}\right)_{3}(\mathrm{M}=\mathrm{Ti}, \mathrm{Fe}, \mathrm{V})^{3,11-13}$ and $\mathrm{Na}_{3} \mathrm{~V}_{2}\left(\mathrm{PO}_{4}\right)_{2} \mathrm{~F}_{3}{ }^{14,15}$ reported. In particular, $\mathrm{Na}_{3} \mathrm{~V}_{2}\left(\mathrm{PO}_{4}\right)_{3}$ (NVP) has been demonstrated recently as a prospective cathode material for use as sodium ion ${ }^{3,12,16}$ or hybrid-ion batteries (HIB) ${ }^{17}$ while the composition of phosphate-based Na-insertion hosts is advantageous due to the strong covalent $\left(\mathrm{PO}_{4}\right)^{3-}$ units that provide structural stability even at high charge states and address thermal safety concerns unlike commercial Li-insertion oxide hosts. ${ }^{13,18,19}$ Furthermore, its intrinsically well-defined NASICON channel structure facilitates excellent ionic conductivity ${ }^{1}$ and results in useful performances in terms of specific capacity, rate capability and cycle life. Furthermore, various analyses at different temperatures have shown that NVP holds good thermal stability, thus suggesting the safe nature of this material which is also critical for large-scale utility grid applications. ${ }^{20}$

NVP displays two potential plateaus at $3.4 \mathrm{~V}$ and $1.6 \mathrm{~V} v s$. $\mathrm{Na}^{+} / \mathrm{Na}$, related to the $\mathrm{V}^{3+} / \mathrm{V}^{4+}$ and $\mathrm{V}^{2+} / \mathrm{V}^{3+}$ redox couples, and 
these two reaction voltages correspond to a specific capacity of 117 and $50 \mathrm{~mA} \mathrm{~h} \mathrm{~g}{ }^{-1}$ for the high and low voltage zones, respectively. Lim et al. has correlated these two plateaus with the energies calculated for different $\mathrm{Na}$ distributions in the phase, from which a two-phase reaction is expected to form two energetically favorable phases. ${ }^{20}$ There are two crystallographic sites to accommodate Na ions in NVP compound, of which the $\mathrm{Na}(1)$ site is proved to remain totally occupied with one $\mathrm{Na}$ ion while the $\mathrm{Na}(2)$ site is active when the sodium content changes from $\mathrm{Na}_{3} \mathrm{~V}_{2}\left(\mathrm{PO}_{4}\right)_{3}$ to $\mathrm{NaV}_{2}\left(\mathrm{PO}_{4}\right)_{3}$ in a specialised voltage range. However, the extraction of all three $\mathrm{Na}$ ions with a theoretical capacity of $176 \mathrm{~mA} \mathrm{~h} \mathrm{~g}{ }^{-1}$ is kinetically difficult due to the much lower electronic/ionic conductivity of the end-member of $\mathrm{V}_{2}\left(\mathrm{PO}_{4}\right)_{3},{ }^{17,21}$ therefore two-thirds of the ions are capable to be reversibly extracted/inserted and give rise to a theoretical capacity of $117 \mathrm{~mA} \mathrm{~h}^{-1}$. For this NASICON structure, a $\mathrm{Na}_{4} \mathrm{~V}_{2}\left(\mathrm{PO}_{4}\right)_{3}$ phase could be formed if all three $\mathrm{Na}(2)$ sites are occupied by $\mathrm{Na}$ ions with a resulting theoretical capacity of $234 \mathrm{~mA} \mathrm{~h} \mathrm{~g}^{-1}$ provided four Na per formula could extracted.

To the best of our knowledge, only one paper has reported the highest value of $234 \mathrm{~mA} \mathrm{~h} \mathrm{~g}{ }^{-1}$ utilizing NVP cathodes. ${ }^{13}$ $\mathrm{Na}_{3} \mathrm{~V}_{2}\left(\mathrm{PO}_{4}\right)_{3}$ can be considered as a promising cathode material exhibiting a high capacity and voltage range $(3.7 \mathrm{~V}$ and $1.9 \mathrm{~V} v s$. $\left.\mathrm{Li}^{+} / \mathrm{Li}\right)$. Herein, a solution-based carbothermal reduction method (S-CTR) is adopted as an improved synthetic methodology compared with carbothermal reduction (CTR) approaches to fabricate NVP materials. Based on the configuration of a $\mathrm{NVP} / \mathrm{LiPF}_{6} / \mathrm{Li}$ hybrid-ion battery, a high capacity of $170 \mathrm{~mA} \mathrm{~h} \mathrm{~g}{ }^{-1}$ is produced with good C-rate and cycling performances.

\section{Experimental}

A developed CTR synthetic methodology, named S-CTR was employed for the preparation of the NVP which involves the following steps. $1.41 \mathrm{~g} \mathrm{Na} \mathrm{CO}_{3}, 2.5 \mathrm{~g} \mathrm{NH}_{4} \mathrm{H}_{2} \mathrm{PO}_{4}$ and $1.32 \mathrm{~V}_{2} \mathrm{O}_{5}$ were used in stoichiometric proportions to form a mixed solution by stirring in $50 \mathrm{~mL}$ distilled water. This mixture was then dried at $50{ }^{\circ} \mathrm{C}$ via forced-air drying with the obtained solid ground by adding $0.34 \mathrm{~g}$ of an acetylene black powder. All the reagents used were of the highest analytical purity available and were used without any further purification. The precursor was preheated at $350{ }^{\circ} \mathrm{C}$ in flow argon for $4 \mathrm{~h}$, reground and re-fired at 650,700 and $750{ }^{\circ} \mathrm{C}$ in argon atmosphere for $8 \mathrm{~h}$, respectively. NVP was prepared by a CTR methodology as in accordance with the literature ${ }^{21}$ to provide a critical comparison.

In order to obtain the crystal structure of the compound, $\mathrm{X}$-ray powder diffraction (XRD) analyses were performed by using a Bruker D8 diffractometer with monochromatic $\mathrm{Cu} \mathrm{K} \alpha$ radiation $(\lambda=1.5406 \AA)$, and the diffraction data was recorded in the $2 \theta$ range of $10-60^{\circ}$ with a scan rate of $8^{\circ}$ per min. The infrared (IR) spectra was obtained using an FT-IR Spectrometer (Jasco, FT/IR-4100, Japan) under transmission mode based on the $\mathrm{KBr}$ pellet method in the range of $500-2000 \mathrm{~cm}^{-1}$. The particle morphology of the composite was investigated by a FEI Quanta 200 scanning electron microscopy (SEM).
The thermogravimetric analysis (TG) of the samples was carried on a Diamond TG thermo-analyzer.

The cathode electrode was composed of active NVP material, acetylene black, and binder (Polyvinylidene Fluoride, PVDF) in a weight ratio of $8: 1: 1$ by using NMP as solvent and an aluminum foil as current collector $\left(\sim 4.5 \mathrm{mg} \mathrm{cm}{ }^{-2}\right)$, followed by drying in vacuum at $110{ }^{\circ} \mathrm{C}$ for $24 \mathrm{~h}$. To evaluate the electrochemical properties, a R2016 coin cell was assembled in an argon-filled glove box using metallic lithium as anode, Celgard 2500 membrane as separator. The electrolyte was $1 \mathrm{M} \mathrm{LiPF}_{6}$ dissolved in a mixture of ethylene carbonate (EC), dimethyl carbonate (DMC), diethyl carbonate (DEC) (v/v/v, 1/1/1).

Cyclic voltammetry (CV) and galvanostatic charge-discharge cycling tests were carried out in a setting voltage range by using an electrochemical workstation (CHI660C) and CT2001A LAND battery tester, respectively. Electrochemical impedance spectroscopy (EIS) was studied using a Modulab (Solartron Analytical) with the amplitude of $5 \mathrm{mV}$ in the frequency range from $1 \mathrm{MHz}$ to $10 \mathrm{mHz}$. All electrochemical tests were carried out at room temperature.

\section{Results and discussion}

The power XRD patterns of NVP prepared by S-CTR and CTR at 650 and $700{ }^{\circ} \mathrm{C}$ are shown in Fig. 1a, respectively. For comparison, all of the diffraction peaks are indexed to the $R \overline{3} c$ space group (Rhombohedral unit with $2 \mathrm{Na}$ in $18 \mathrm{e}$ position and $1 \mathrm{Na}$ in $6 \mathrm{~b}$ position) and are in good agreement with the results of the NASICON framework. ${ }^{3,9,12}$ Clearly, no redundant peaks at 17 and $30.2^{\circ}$ have appeared for the sample prepared by S-CTR when compared with the XRD patterns from CTR sample. This could indicate the formation of a pure NVP mainly on account of the solution-based admixture by improving particle contact when stirred, as undertaken as part of the synthetic methodology (see Experimental). Fig. 1b shows the FT-IR analysis of S-CTR NVP which is in good agreement with Jang's work, ${ }^{20}$ from which the bands indicate good crystallization due to the observation of peaks present; the bands at 578 and $1048 \mathrm{~cm}^{-1}$ suggest the presence of $\mathrm{P}-\mathrm{O}$ bonds of $\mathrm{PO}_{4}$ tetrahedra and the vibration from $\mathrm{V}^{3+}-\mathrm{O}^{2-}$ bonds in isolated $\mathrm{VO}_{6}$ octahedra are evident at $630 \mathrm{~cm}^{-1}$. Moreover, the infrared bands in the range of $1150-1250 \mathrm{~cm}^{-1}$ can be attributed to the stretching vibration of terminal $\mathrm{PO}_{4}$ units, ${ }^{22}$ while the bands at 760 and $950 \mathrm{~cm}^{-1}$ which are characteristic of the occurrence of $\mathrm{V}^{5+}$ in $\mathrm{VO}_{6}$ octahedra were not observed indicating that the $\mathrm{V}^{5+}$ in $\mathrm{V}_{2} \mathrm{O}_{5}$ have been reduced to $\mathrm{V}^{3+}$ in NVP. Thus, the combined results of XRD and FT-IR demonstrate the rhombohedral NASICON characteristic of S-CTR NVP. The corresponding crystal structure was simulated and presented in the inset of Fig. 1b. The structural image shows that the octahedral $\mathrm{VO}_{6}$ interlinks via corners with tetrahedral $\mathrm{PO}_{4}$ to establish the polyanion $\left[\mathrm{V}_{2}\left(\mathrm{PO}_{4}\right)_{3}\right]$ units in the $c$-axis direction which were interconnected through $\mathrm{PO}_{4}$ to the same neighboring units, and each primitive cell of NVP contains six formula units built up from $\left[\mathrm{V}_{2}\left(\mathrm{PO}_{4}\right)_{3}\right]$ framework anion and two different oxygen environment sodium 

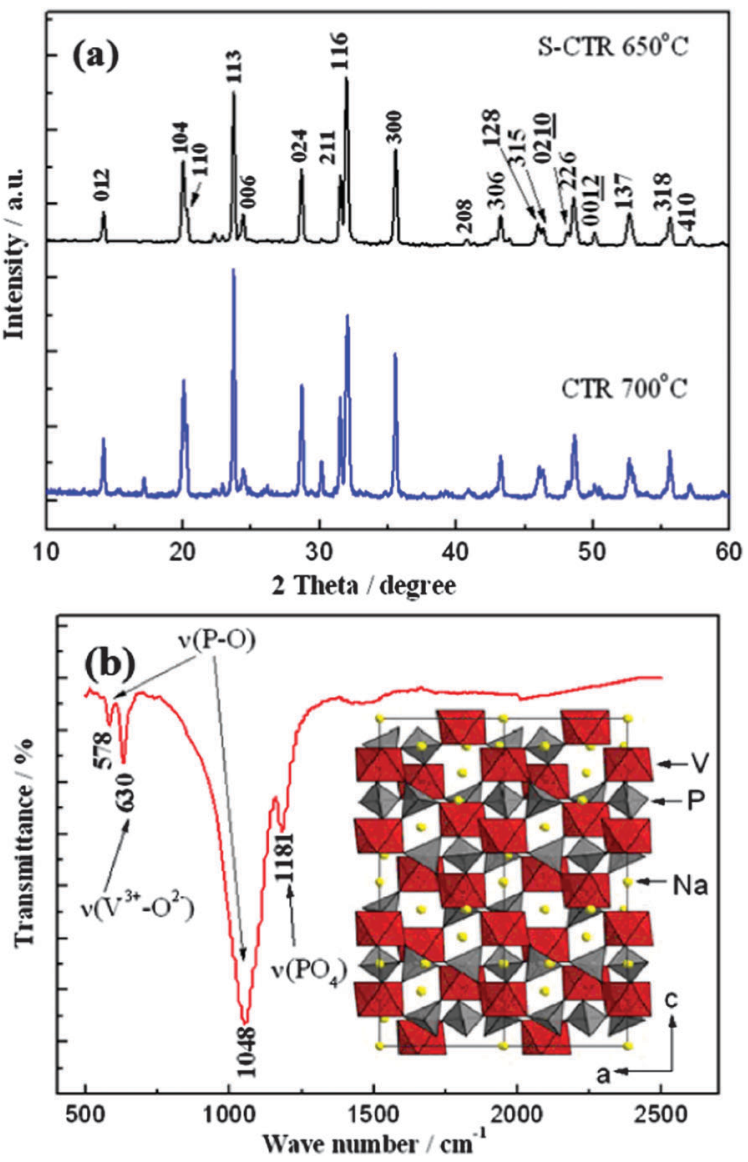

Fig. 1 (a) Power XRD patterns of the as-prepared NVP by S-CTR at $650^{\circ} \mathrm{C}$ and CTR at $700{ }^{\circ} \mathrm{C}$, (b) FI-IR spectrum of NVP synthesized by S-CTR at $650{ }^{\circ} \mathrm{C}$, the inset shows the corresponding rhombohedral structure.

atoms, of which the first one is six fold coordination $[\mathrm{Na}(1)]$ and the other is eight fold coordination $[\mathrm{Na}(2)]$.

The morphology and surface structure of the S-CTR NVP was characterized by SEM with the images depicted in Fig. 2. It is clearly that nano-particles are adhered to the surface of the bulk material where the irregularly shaped particles are distributed over the size range of $1-5 \mu \mathrm{m}$, likely as a result from the

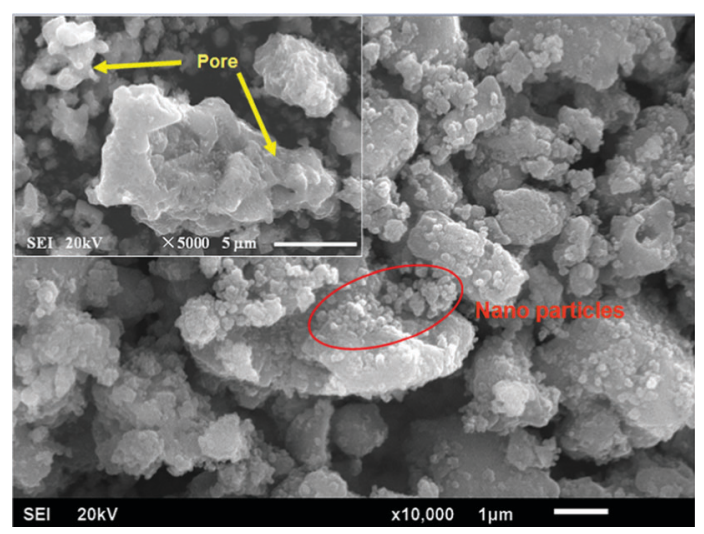

Fig. 2 SEM images of NVP by S-CTR at $650{ }^{\circ} \mathrm{C}$, the inset shows a partial image of the particles.

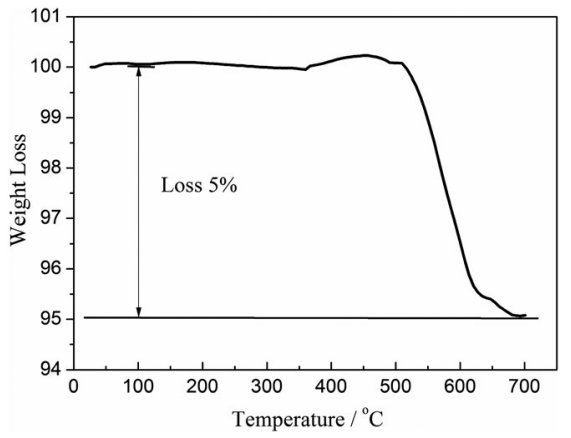

Fig. 3 TG curves of the NVP sample in air atmosphere.

molecular mixing and mechanically chemical activation processes applied before sintering. Additionally, the malformed surface structures, as shown in the inset of Fig. 2, along with the secondary particles formed by particle agglomeration have resulted in NVP exhibiting many pores which can be useful for the facilitation of electrolyte ions transport. ${ }^{15}$ Furthermore, the growth of NVP particles is considered to be hindered by the amount of available source of carbon from CTR methodology as evidence by measuring the residual carbon with a content of $5 \%$ in the NVP-C composite calculated to be $\sim 5 \%$ from TG curves as shown in Fig. 3 and will contribute to improve the electron transport between particles, which further enhance the power density. Graphene has been used as conducting support for olivine-based $\mathrm{LiFePO}_{4}$ batteries with negligible fading even after several hundreds of cycles, ${ }^{23}$ and would also be appropriate for use in NVP battery due to its favorably structural impacts on electrochemical performances. ${ }^{24}$ Additionally graphene-based nanomaterials for energy storage have been reviewed ${ }^{25}$ displaying the progresses of battery properties by utilizing graphene.

Hybrid-ion batteries have been described by Barker et al. ${ }^{26}$ who investigated the mixed $\mathrm{Na} / \mathrm{Li}$ insertion/extraction mechanism, and an analogical work based on the NVP/Li hybrid-ion battery has been explored recently. ${ }^{21}$ Fig. 4 shows the anterior eight $\mathrm{CV}$ cycles at a scan rate of $0.5 \mathrm{mV} \mathrm{s}^{-1}$ in a voltage range from 2 to $4.8 \mathrm{~V}$ vs. $\mathrm{Li}^{+} / \mathrm{Li}$. The anodic reaction could be attributed to $\mathrm{Na}$ extraction in the first cycle with an anodic peak present while the sequential cathodic processes with only one voltammetric peak indicates a $\mathrm{Na} / \mathrm{Li}$ hybrid-ion insertion as a result of the irreversibility of $\mathrm{Na}$ ion and the vast excess of $\mathrm{Li}$ in this hybrid-ion system. One couple of redox peaks would be presented provided that the inserted ions are all $\mathrm{Na}$ as depicted in a sodium-ion battery. ${ }^{27}$ As described previously, ${ }^{17,21}$ the redox couple in this voltage range is assigned to the $\mathrm{V}^{3+} / \mathrm{V}^{4+}$ reaction which is accompanied by migration of two mixed alkali ions. Interestingly, the voltammetric cycles have presented only one redox couple indicating that mixed ion behavior has become predominantly Li-ion transport in the cycling, with the exhibited excellent symmetry of the 4th and 8th CV curves also demonstrating good reversibility of the material. ${ }^{17}$ Combined with our previous analysis, the utilized NVP electrode could produce an easy and adequate ion-exchange with Li-based electrolytes undergoing potential cycling or standing process for the formation of 


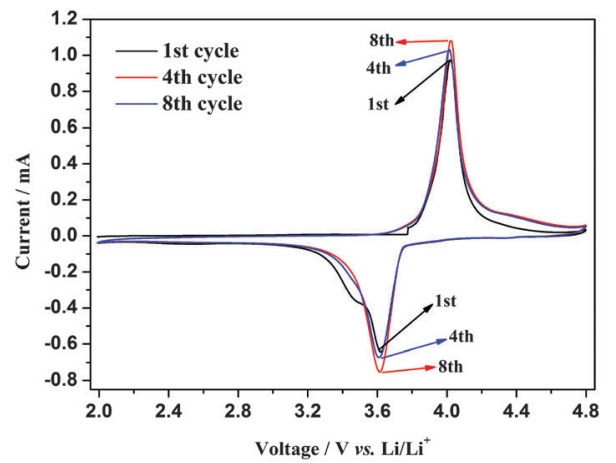

Fig. 4 Anterior eight CV cycles of S-CTR NVP at $0.5 \mathrm{mV} \mathrm{s}^{-1}$ in a voltage range of $2-4.8 \mathrm{~V}$ vs. $\mathrm{Li}^{+} / \mathrm{Li}$.

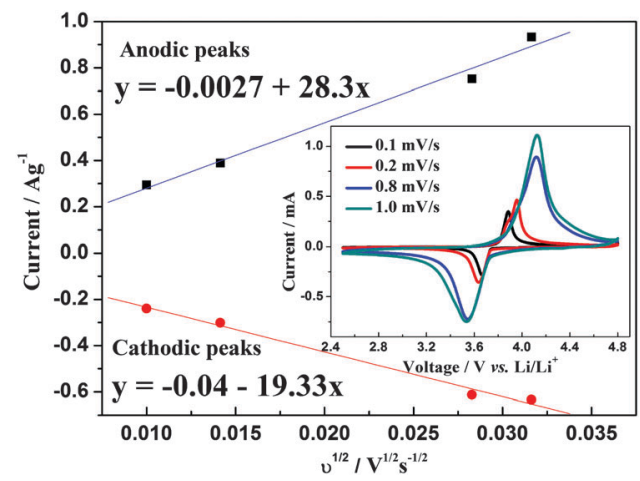

Fig. 5 The corresponding relationship between the square root of the scan rate $V^{1 / 2}$ and peak current $i_{\mathrm{p}}$, the inset shows CV curves at different scan rates of S-CTR NVP after $10 \mathrm{CV}$ cycles in a voltage range of $2.5-4.8 \mathrm{~V}$ vs. $\mathrm{Li}^{+} / \mathrm{Li}$.

$\mathrm{Li}_{2} \mathrm{NaV}_{2}\left(\mathrm{PO}_{4}\right)_{3}{ }^{21}$ while the exchanged $\mathrm{Na}$ ion prefers to be at $\mathrm{Na}(2)$ sites. $^{10}$

The hybrid-ion battery after proceeding $10 \mathrm{CV}$ cycles at $0.5 \mathrm{mV} \mathrm{s}^{-1}$ in a voltage range of $2.5-4.8 \mathrm{~V} v s . \mathrm{Li}^{+} / \mathrm{Li}$, continued to be tested at $0.1,0.2,0.8$ and $1 \mathrm{mV} \mathrm{s}^{-1}$, respectively, and the results are displayed in the inset of Fig. 5 . The phase of $\mathrm{Li}_{2} \mathrm{NaV}_{2}\left(\mathrm{PO}_{4}\right)_{3}$ could be responsible for the only one obvious redox couple during $\mathrm{CV}$ tests without any visible effects from the insertion/desertion behaviors of $\mathrm{Na}^{+}$ions. The good linear relationships between the square root of the scan rate $v^{1 / 2}$ and peak current $i_{\mathrm{p}}$ depicted in Fig. 5 illustrates a diffusion-controlled process for the electrochemical reaction and a typical equilibrium behavior of an intercalated type electrode. Thus, it is worthwhile to explore the chemical diffusion coefficient for further understanding of NVP electrode. Randles-Sevcik equation (eqn (1)) could be employed to determine the diffusion constant $D$ which describes the relationship between the peak current $i_{\mathrm{p}}$ and the square root of the scan rate $v^{1 / 2}$ :

$$
i_{\mathrm{p}} / m=0.4463\left(F^{3} / R T\right)^{1 / 2} n^{3 / 2} A D^{1 / 2} C v^{1 / 2}
$$

where $m$ is the mass of active cathode material, $F$ the Faraday constant, $R$ the gas constant, $T$ the absolute temperature, $n$ the number of electrons in reaction $(n=2), A$ the effective contact area between electrode and electrolyte $\left(0.79 \mathrm{~cm}^{2}\right)$ and $C$ is the concentration of alkali ion in the cathode calculated from the crystallographic cell parameter of NVP. $D$ values of the anodic and cathodic reactions are calculated as $2.73 \times 10^{-10} \mathrm{~cm}^{2} \mathrm{~s}^{-1}$ and $1.28 \times 10^{-10} \mathrm{~cm}^{2} \mathrm{~s}^{-1}$, respectively. The values which have been regarded as $\mathrm{Li}$ ion diffusion from/into $\mathrm{NaLi}_{2} \mathrm{~V}_{2}\left(\mathrm{PO}_{4}\right)_{3}{ }^{21}$ are much smaller than that in a $\mathrm{Li}_{3-x} \mathrm{~V}_{2}\left(\mathrm{PO}_{4}\right)_{3}(x=2)$ with a high magnitude of $10^{-8} \mathrm{~cm}^{2} \mathrm{~s}^{-1}$. This might indicate that hybrid-ion diffusion exists slowing the diffused rate as a result of the larger radius and mass for Na ions. In addition, the framework leading to Na ion migration of NVP could be considered capable to easily facilitate the transport of $\mathrm{Li}$ ions theoretically which would produce a larger $D$ value. $\mathrm{NaLi}_{2} \mathrm{~V}_{2}\left(\mathrm{PO}_{4}\right)_{3}$ has been demonstrated to be formed successfully by ion-exchange or cycling, ${ }^{10,17,21}$ thus suggesting that the existed Na ions might not smoothly complete the insertion reaction but produce an impeding effects on $\mathrm{Li}$ ion transport when hybrid $\mathrm{Na} / \mathrm{Li}$ ions participate in the electrochemical reactions.

As shown in Fig. 6a the hybrid-ion batteries using S-CTR NVP prepared at 650,700 and $750{ }^{\circ} \mathrm{C}$ display an initial discharge capacity of 122,117 and $96 \mathrm{~mA} \mathrm{~h} \mathrm{~g}^{-1}$, respectively, at $0.1 \mathrm{C}$ (Note that $0.1 \mathrm{C}$ refers to two Na extraction from the NVP per formula unit in $10 \mathrm{~h}$ ) in a voltage range of $2.5-4.8 \mathrm{~V} v \mathrm{~s} . \mathrm{Li} / \mathrm{Li}^{+}$, demonstrating a better performance of NVP prepared at optimized $650{ }^{\circ} \mathrm{C}$. Under the same hybrid-ion system, NVP prepared by S-CTR at $650{ }^{\circ} \mathrm{C}$ could exhibit a higher initial discharge capacity of $156 \mathrm{~mA} \mathrm{~h} \mathrm{~g}^{-1}$ than that prepared by CTR at $700{ }^{\circ} \mathrm{C}$ with a capacity of $147 \mathrm{~mA} \mathrm{~h} \mathrm{~g}^{-1}$ at $0.1 \mathrm{C}$ between 1.6 and $4.6 \mathrm{~V} v s . \mathrm{Li} / \mathrm{Li}^{+}$ as shown in Fig. 6b, mainly resulting from the improved
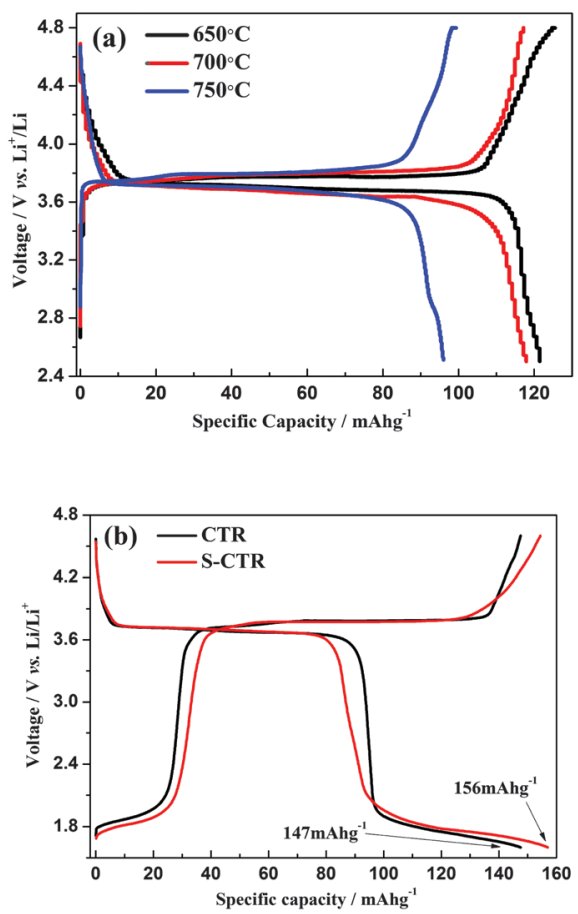

Fig. 6 Initial charge-discharge profiles of hybrid-ion batteries at a current density of $0.1 \mathrm{C}$. (a) The performances of cathode using S-CTR NVP prepared at 650,700 and $750{ }^{\circ} \mathrm{C}$, (b) the compared results of CTR NVP prepared at $700{ }^{\circ} \mathrm{C}$ and S-CTR NVP prepared $650^{\circ} \mathrm{C}$. 

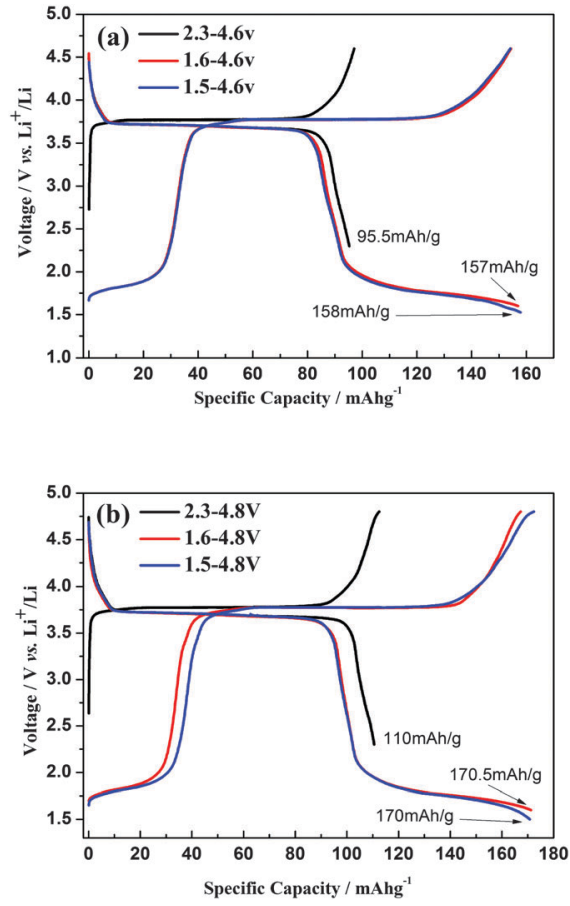

Fig. 7 Initial charge-discharge profiles of S-CTR NVP prepared at $650{ }^{\circ} \mathrm{C}$ at $0.1 \mathrm{C}$ within a voltage range of (a) $1.5,1.6,2.3-4.6 \mathrm{~V} v \mathrm{~s}$. Li//ii ${ }^{+}$, (b) 1.5, 1.6, $2.3-4.8 \vee v s . \mathrm{Li} / \mathrm{Li}^{+}$.

synthesized method for NVP. Additionally in order to obtain a large specific capacity of NVP in a hybrid-ion battery, various voltage windows, which could decide the inserted/extracted ion number for NVP, were applied to explore the exhibited electrochemical performances as shown in Fig. 7 and Fig. 8. The hybrid-ion batteries using S-CTR NVP cathodes displayed the initial discharge capacities of $158,157,96 \mathrm{~mA} \mathrm{~h} \mathrm{~g}^{-1}$ from 1.5 , 1.6, 2.3 to $4.6 \mathrm{~V}$ vs. $\mathrm{Li}^{-\mathrm{Li}^{+}}$(Fig. 7a), and $170,170,110 \mathrm{~mA} \mathrm{~h} \mathrm{~g}{ }^{-1}$ from $1.5,1.6,2.3$ to $4.8 \mathrm{~V} v s$. $\mathrm{Li}^{-\mathrm{Li}^{+}}$(Fig. $7 \mathrm{~b}$ ), respectively. The cycling performances at various C-rates of NVP in a voltage range of 1.6-4.6 V vs. $\mathrm{Li}^{-\mathrm{Li}^{+}}$for S-CTR NVP could be thought to be satisfying compared with those for CTR NVP. The average discharge capacities are 156, 138, 116, 95 and $80 \mathrm{~mA} \mathrm{~h} \mathrm{~g}^{-1}$ for S-CTR NVP and 126, 110, 75, 64 and $56 \mathrm{~mA} \mathrm{~h} \mathrm{~g}^{-1}$ for CTR NVP at $0.1,0.2,0.5,1$ and $2 \mathrm{C}$, respectively, as shown in Fig. 8a. Meanwhile, a discharge capacity of $124 \mathrm{~mA} \mathrm{~h} \mathrm{~g}{ }^{-1}$ for the 140th galvanostatic cycles was also displayed. Interestingly, Fig. $8 \mathrm{~b}$ has depicted acceptable cycling performances for this hybrid-ion battery with a discharge capacity of $140 \mathrm{~mA} \mathrm{~h} \mathrm{~g}{ }^{-1}$ after 50 cycles at $0.1 \mathrm{C}$ when the utilized voltage rises to $4.8 \mathrm{~V} v$ s. $\mathrm{Li}^{-\mathrm{Li}^{+}}$.

As far as we know, there are still few reports corresponding to the electrochemical data toward to NVP, and these compared values reported in related literatures have been listed in Table 1.

Next, EIS was further used to investigate the electrochemical kinetics of NVP electrode when it is cycled after 1, 20 and 50 cycles and charged to a same voltage of $3.7 \mathrm{~V}$. The Nyquist plots and corresponding fitted equivalent circuit model are presented in Fig. 9(a and b). All the impedance parameters with relative
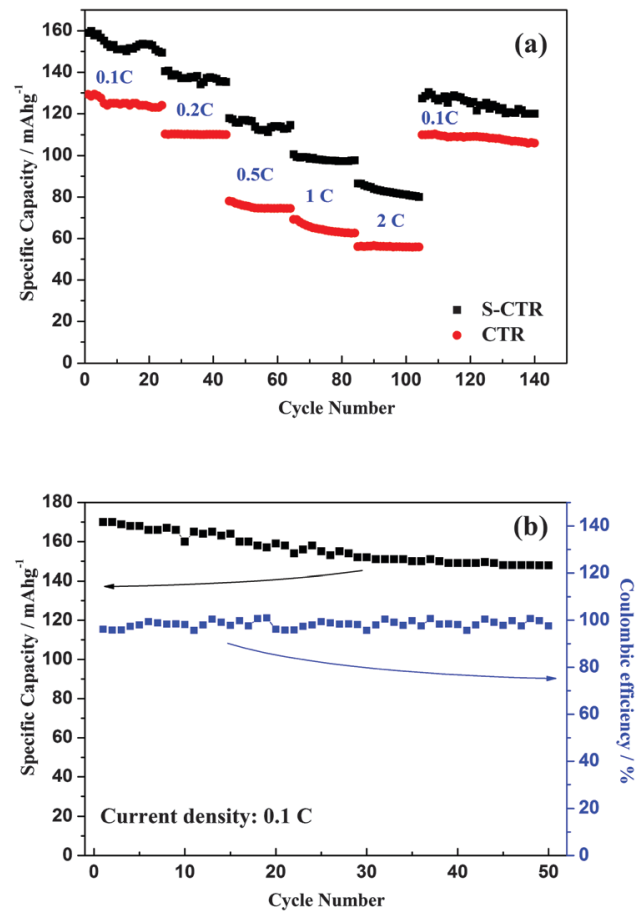

Fig. 8 (a) Cycling performances at various $\mathrm{C}$-rates for S-CTR and CTR NVP in a voltage range of $1.6-4.6 \mathrm{~V} v$. $\mathrm{Li}^{\prime} \mathrm{Li}^{+}$, and (b) at $0.1 \mathrm{C}$ for S-CTR NVP between 1.6 and $4.8 \mathrm{~V}$ vs. Li/Li ${ }^{+}$.

Table 1 Reported capacities of NVP for use in SIB and HIB

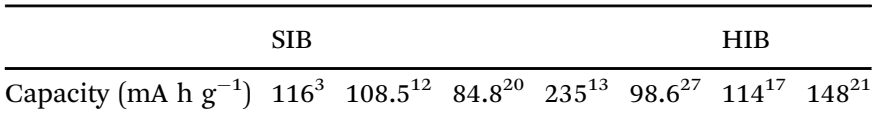

errors estimate (\%) of the fitting equivalent circuit are listed in Table 2 by using ZSimWin software with each chi-squared function $\left(\chi^{2}\right)$ less than $10^{-4}$, by which the value of chi-squared
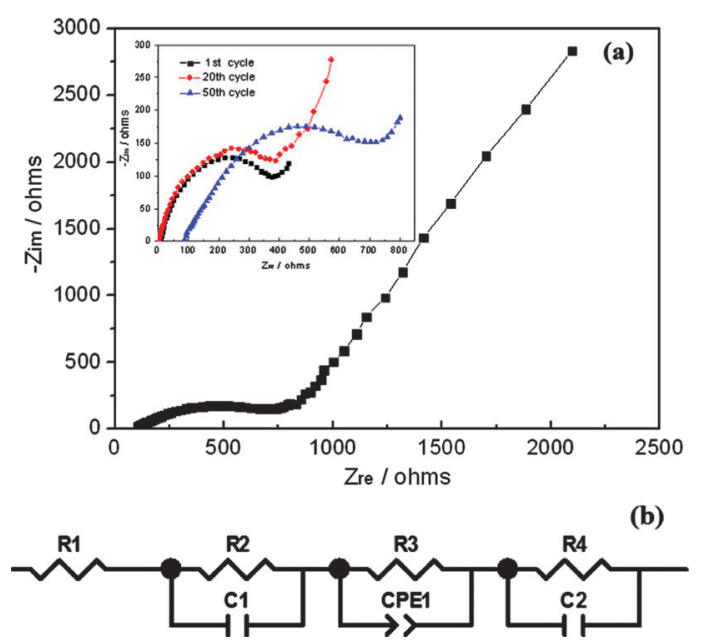

Fig. 9 (a) Nyquist plots of the hybrid-ion battery charged to $3.7 \mathrm{Vvs}$. $\mathrm{Li}^{+} / \mathrm{Li}$ after 50 galvanostatic cycles, the inset shows the compared Nyquist plots of the battery after 1, 20 and 50 cycles. (b) The equivalent circuit model. 
Table 2 Impedance parameters of the fitting equivalent circuit from the cell undergoing cycles as denoted in the low right corner

\begin{tabular}{llllllll}
\hline & $R_{1}\left(\Omega \mathrm{cm}^{-2}\right)$ & $R_{2}\left(\Omega \mathrm{cm}^{-2}\right)$ & $C_{1}\left(\mathrm{~F} \mathrm{~cm}^{-2}\right)$ & $R_{3}\left(\Omega \mathrm{cm}^{-2}\right)$ & CPE1 $\left(\mathrm{Ss}^{1 / 2} \mathrm{~cm}^{-2}\right)$ & $R_{4}\left(\Omega \mathrm{cm}^{-2}\right)$ & $C_{2}\left(\mathrm{~F} \mathrm{~cm}^{-2}\right)$ \\
\hline Results & 85.34 & 367.6 & $7.6 \times 10^{-4}$ & 826.7 & $3.86 \times 10^{-5}$ & 93.1 \\
Error (\%) & 1.534 & 7.291 & 6.068 & 1.17 & 4.548 & $6.3 \times 10^{-4}$ \\
& & & & & 5.78 & 1.769
\end{tabular}

function between $10^{-5}$ and $10^{-4}$ could provide a reasonably good indication of the quality of the fit. ${ }^{28} R_{1}$ represents the internal resistance involving the resistance of the electrolyte and electrode which is denoted as the small intercept at the $Z_{\mathrm{re}}$ axis. $R_{2}$ corresponds to the resistance of SEI film as depicted in the high frequency region of the semi-circle, while $C_{1}$ signifies the resultant capacitance from SEI film. $R_{3}$ is the charge transfer resistance in the intermediate-frequency region and CPE1 is related to the surface property of the electrode. $R_{4}$ denotes the Warburg resistance originated from the diffusion of $\mathrm{Na}^{+}$ions in the electrode bulk as depicted in the low frequency region of the sloping line. $C_{2}$ demonstrate the double layer capacitance caused by ion transfer in the electrode material. As can be observed from inspection of Fig. 9a, the internal resistance and charge transfer resistance of the 50th cycle are obviously increasing compared with that of the 1st and 20th cycle, which could be attributed to the cycling influence. In addition, the nearly $45^{\circ}$ sloping line of Nyquist plots at low frequency corresponding to the solid-state diffusion of ions in the active materials, further confirmed the electrochemistry process of NVP as a diffusion-controlled rather than surface-controlled reaction.

As shown in Scheme 1, two kinds of crystalline Na sites namely $\mathrm{Na}(1)$ and $\mathrm{Na}(2)$ sites are displayed, of which one $\mathrm{Na}(1)$ site retains to be occupied by $\mathrm{Na}$ ion while two $\mathrm{Na}(2)$ sites are occupied by $\mathrm{Li}$ ions resulting from the ion-exchange occurring in cycling or standing exchange. This description could be thought appropriately due to the ion-transport mechanism suggested by Goodenough et al. ${ }^{10}$ and our previous works. ${ }^{21}$ According to this conclusion, $\mathrm{NaLi}_{2} \mathrm{~V}_{2}\left(\mathrm{PO}_{4}\right)_{3}$ could be reasonably formed from NVP by ion exchange with Li ions, while the left $\mathrm{Na}$ ion could be considered stationary at $\mathrm{Na}(1)$ site. The exchanged Li ions are able to occupy the two $\mathrm{Na}(2)$ sites which held $\mathrm{Na}$ ions before, or re-exchange only between these two sites.

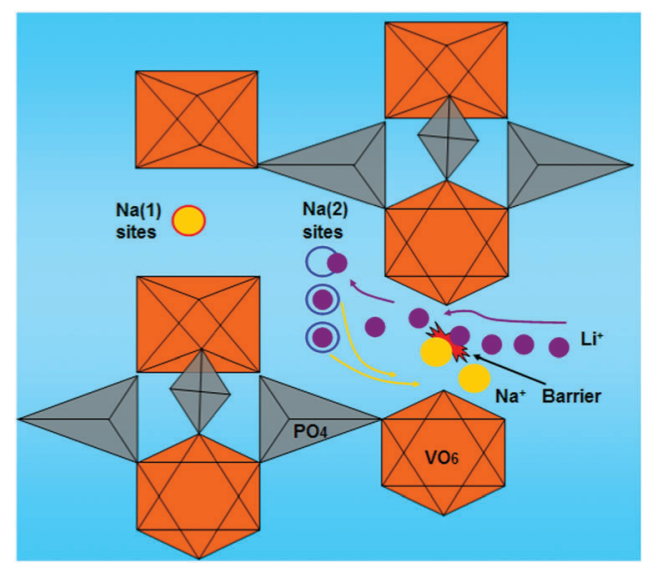

Scheme 1 Representation of NASICON-structure NVP exhibiting the ionexchange for $\mathrm{Na}$ with Li ions and the Li-insertion process.
The ion-exchange mechanism for $\mathrm{NaLi}_{2} \mathrm{~V}_{2}\left(\mathrm{PO}_{4}\right)_{3}$ is firstly demonstrated in eqn (2) and (3), where the number in parentheses denotes the alkali ions in $\mathrm{Na}(1)$ or $\mathrm{Na}(2)$ sites, the value in the bottom right corner signifies series number of the ions and $\gamma$ represents a vacancy in $\mathrm{Na}(2)$ sites.

$$
\begin{aligned}
& \mathrm{Na}_{1}^{+}(2)+\mathrm{Na}_{2}^{+}(2)+\gamma(2)+\mathrm{Na}^{+}(1)+2 \mathrm{Li}^{+} \\
& \rightarrow \mathrm{Na}^{+}(1)+\gamma(2)+\mathrm{Li}_{1}^{+}(2)+\mathrm{Li}_{2}{ }^{+}(2)+2 \mathrm{Na}^{+} \\
& \mathrm{Li}_{1}^{+}(2)+\mathrm{Li}_{2}^{+}(2)+\gamma(2)+\mathrm{Na}^{+}(1)+\mathrm{Li}^{+} \\
& \rightarrow \mathrm{Na}^{+}(1)+\gamma(2)+\mathrm{Li}_{1}^{+}(2)+\mathrm{Li}_{2}^{+}(2)+\mathrm{Li}^{+} \\
& \mathrm{Li}_{1}^{+}(2)+\mathrm{Li}_{2}^{+}(2)+\mathrm{Li}_{3}^{+}(2)+\mathrm{Na}^{+}(1)+\mathrm{Li}^{+} \\
& \rightarrow \mathrm{Na}^{+}(1)+\mathrm{Li}_{1}{ }^{+}(2)+\mathrm{Li}_{2}^{+}(2)+\mathrm{Li}_{3}^{+}(2)+\mathrm{Li}^{+}
\end{aligned}
$$

However, the vacancy at $\mathrm{Na}(2)$ site has been thought capable to be shoehorned with one alkali ion by electrochemical means, such as an enlarged voltage window. ${ }^{21}$ Fig. 10 exhibits the electrochemical voltage-composition curves of the first galvanostatic cycle at a current rate of $0.1 \mathrm{C}$ for NVP hybrid-ion battery in a voltage range of $1.6-4.8 \mathrm{~V}$ vs. $\mathrm{Li} / \mathrm{Li}^{+}$, of which the inserted alkali ions are presumably as $\mathrm{Li}$ ions. The different number of ions $(\Delta x)$ in charge (1.7) and discharge (1.4) around the plateau of near 3.7 V demonstrates a hybrid-ion extraction/insertion behavior composed by union-exchanged $\mathrm{Na}^{+}$ions and ion-exchanged $\mathrm{Li}^{+}$ions, because the irreversibility mainly from SEI resistance for $\mathrm{Na}^{+}$ions would cost larger energy (charging capacity) to make ion migrate, but smaller and lighter $\mathrm{Li}^{+}$ions have substituted $\mathrm{Na}^{+}$ions to insert into the NASICON structure which only need less energy (discharging capacity). Up until the discharging voltage of $1.6 \mathrm{~V}$, the number of lithium ions $(x)$ in $\mathrm{NaLi}_{x} \mathrm{~V}_{2}\left(\mathrm{PO}_{4}\right)_{3}$ is about 2.9 and two-phase transitions assigned to $\mathrm{V}^{3+} / \mathrm{V}^{4+}$ and $\mathrm{V}^{2+} / \mathrm{V}^{3+}$ redox reactions should be responsible for this result. The first transition is divided into two ion-insertion steps corresponding two discharge plateaus, of which the insertion of two ions is completed until $1.9 \mathrm{~V} v$ s. $\mathrm{Li}^{\prime} / \mathrm{Li}^{+}$and the

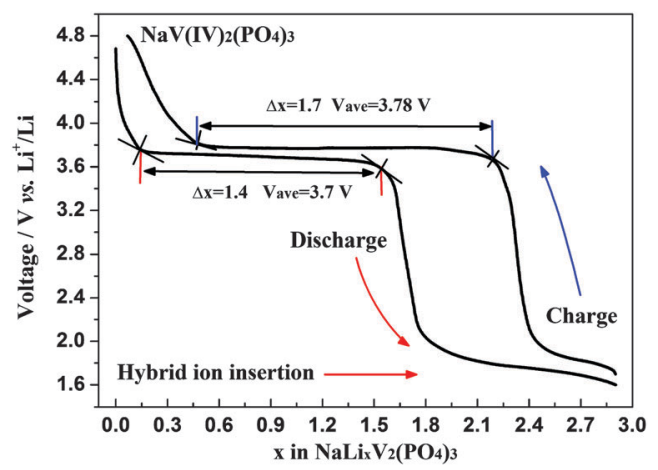

Fig. 10 Electrochemical voltage-composition curves of the first galvanostatic cycle at a current rate of $0.1 \mathrm{C}$ for NVP hybrid-ion battery. 
second transition realizing a mixed V(II/III) would rationally be ascribed to the inserted 0.9 ion until the cut-off voltage of $1.6 \mathrm{~V} v s$. $\mathrm{Li} / \mathrm{Li}^{+}$. By employing Faraday's Law $\left(C=26.8 n / M \mathrm{~A} \mathrm{~h}{ }^{-1}\right.$, where $C$ is the theoretical capacity of the active material, $n$ is the number of electrons in reaction and $M$ is the relative molecular mass) to calculate the discharge capacity when $2.9 \mathrm{Li}$ ions are transported, a theoretical value of $181 \mathrm{~mA} \mathrm{~h} \mathrm{~g}^{-1}$ could be obtained which is larger than the experimental figures. One reason, which has been pointed out is that the back ions are mixed with less heavier $\mathrm{Na}^{+}$ions while here, the impeding influences from $\mathrm{Na}$ ions towards $\mathrm{Li}$ ions "barrier" in a synchronous insertion which could be indicated specifically to indicate the lower $D$ as analyzed above. Another probable factor might be the restraint of $\mathrm{Na}$ ions to lower the inserted number of $\mathrm{Li}$ ions attributed to the barrier between them. Actually, the discharge capacity of $170 \mathrm{~mA} \mathrm{~h} \mathrm{~g}{ }^{-1}$ corresponds to an insertion with only $2.7 \mathrm{Li}$ ions, where this overcoming towards to the produced barrier should contribute to the redundant inserted 0.2 ions. It is known that in order to overcome this, significant energy is required which could be attributed to the effects of the insertion of 0.2 ions according to Faraday's Law. Moreover, the inserted ions (excess two) should take up three $\mathrm{Na}(2)$ sites while the vacancy seems prior to be occupied with $\mathrm{Li}$ ion due to the smaller and lighter characters to produce $\mathrm{Li}_{3}^{+}(2)$. The ion of $\mathrm{Li}_{3}^{+}(2)$ is suggested to be difficult to exchange with other ions because this behavior would require significant energy as described by eqn (4), otherwise the vacancy would be occupied with lithium ions to present unstable $\mathrm{NaLi}_{3} \mathrm{~V}_{2}\left(\mathrm{PO}_{4}\right)_{3}$ which is not consistent with ICP results. ${ }^{17,21}$ However, this vacancy has been utilized by ion insertion and a promising cathode material is realized exhibiting $170 \mathrm{~mA} \mathrm{~h} \mathrm{~g}^{-1}$ at a discharge voltage plateau around $3.7 \mathrm{~V}$; as such this material would be suitable for the construction of a high-energy battery.

\section{Conclusion}

A NVP cathode was synthesized with an improved CTR method and used in a hybrid-ion battery to explore its electrochemical properties. The satisfying performances of $170 \mathrm{~mA} \mathrm{~h} \mathrm{~g}^{-1}$ with a discharge voltage plateau around $3.7 \mathrm{~V}$ were presented as a result of the predominantly $\mathrm{Li}$ ion transport in cycling. Reasonably, a $\mathrm{NaLi}_{2} \mathrm{~V}_{2}\left(\mathrm{PO}_{4}\right)_{3}$ phase should be responsible for this properties while the utilization of the three $\mathrm{Na}(2)$ sites for NVP could be associated with the applied voltage windows. Based on the ion-transport mechanism as suggested, two $\mathrm{Na}(2)$ sites can allow the ions to exchange while the last one site with vacancy before could be used to accommodate alkali ions. Meanwhile, a hybrid-ion migration is supported to exist in the whole ion transport, and the adverse effects from $\mathrm{Na}$ ion on the ion diffusion rate and the specific capacity of the hybrid-ion system have been investigated.

\section{Notes and references}

1 M. Armand and J. M. Tarascon, Nature, 2008, 451, 652-657.

2 B. Dunn, H. Kamath and J.-M. Tarascon, Science, 2011, 334, 928-935.
3 K. Saravanan, C. W. Mason, A. Rudola, K. H. Wong and P. Balaya, Adv. Energy Mater., 2013, 3, 444-450.

4 N.-S. Choi, Z. Chen, S. A. Freunberger, X. Ji, Y.-K. Sun, K. Amine, G. Yushin, L. F. Nazar, J. Cho and P. G. Bruce, Angew. Chem., Int. Ed., 2012, 51, 9994-10024.

5 A. S. Arico, P. Bruce, B. Scrosati, J.-M. Tarascon and W. van Schalkwijk, Nat. Mater., 2005, 4, 366-377.

6 B. L. Ellis, W. R. M. Makahnouk, Y. Makimura, K. Toghill and L. F. Nazar, Nat. Mater., 2007, 6, 749-753.

7 A. K. Padhi, K. S. Nanjundaswamy and J. B. Goodenough, J. Electrochem. Soc., 1997, 144, 1188-1194.

8 S.-W. Kim, D.-H. Seo, X. Ma, G. Ceder and K. Kang, Adv. Energy Mater., 2012, 2, 710-721.

9 J. Gopalakrishnan and K. K. Rangan, Chem. Mater., 1992, 4, 745-747.

10 B. L. Cushing and J. B. Goodenough, J. Solid State Chem., 2001, 162, 176-181.

11 H. Kabbour, D. Coillot, M. Colmont, C. Masquelier and O. Mentre, J. Am. Chem. Soc., 2011, 133, 11900-11903.

12 Z. Jian, W. Han, X. Lu, H. Yang, Y.-S. Hu, J. Zhou, Z. Zhou, J. Li, W. Chen, D. Chen and L. Chen, Adv. Energy Mater., 2013, 3, 156-160.

13 J. Kang, S. Baek, V. Mathew, J. Gim, J. Song, H. Park, E. Chae, A. K. Rai and J. Kim, J. Mater. Chem., 2012, 22, 20857-20860.

14 R. A. Shakoor, D.-H. Seo, H. Kim, Y.-U. Park, J. Kim, S.-W. Kim, H. Gwon, S. Lee and K. Kang, J. Mater. Chem., 2012, 22, 20535-20541.

15 W. Song and S. Liu, Solid State Sci., 2013, 15, 1-6.

16 M. D. Slater, D. Kim, E. Lee and C. S. Johnson, Adv. Funct. Mater., 2013, 23, 947-985.

17 K. Du, H. Guo, G. Hu, Z. Peng and Y. Cao, J. Power Sources, 2013, 223, 284-288.

18 F. Cheng, J. Liang, Z. Tao and J. Chen, Adv. Mater., 2011, 23, 1695-1715.

19 H.-K. Song, K. T. Lee, M. G. Kim, L. F. Nazar and J. Cho, Adv. Funct. Mater., 2010, 20, 3818-3834.

20 S. Y. Lim, H. Kim, R. A. Shakoor, Y. Jung and J. W. Choi, J. Electrochem. Soc., 2012, 159, A1393-A1397.

21 W. Song, X. Ji, C. Pan, Y. Zhu, Q. Chen and C. E. Banks, Phys. Chem. Chem. Phys., 2013, 15, 14357-14363.

22 Z. Chen, C. Dai, G. Wu, M. Nelson, X. Hu, R. Zhang, J. Liu and J. Xia, Electrochim. Acta, 2010, 55, 8595-8599.

23 D. Choi, D. Wang, V. V. Viswanathan, I.-T. Bae, W. Wang, Z. Nie, J.-G. Zhang, G. L. Graff, J. Liu, Z. Yang and T. Duong, Electrochem. Commun., 2010, 12, 378-381.

24 W. Song, X. Ji, W. Deng, Q. Chen, C. Shen and C. E. Banks, Phys. Chem. Chem. Phys., 2013, 15, 4799-4803.

25 M. Pumera, Energy Environ. Sci., 2011, 4, 668-674.

26 J. Barker, R. K. B. Gover, P. Burns and A. J. Bryan, J. Electrochem. Soc., 2007, 154, A882-A887.

27 Z. Jian, L. Zhao, H. Pan, Y.-S. Hu, H. Li, W. Chen and L. Chen, Electrochem. Commun., 2012, 14, 86-89.

28 M. Umeda, K. Dokko, Y. Fujita, M. Mohamedi, I. Uchida and J. R. Selman, Electrochim. Acta, 2001, 47, 885-890. 